\title{
Analisis Strategi Bisnis dengan Business Model Canvas pada Zocha Handicraft Akar Wangi Garut
}

\author{
Dani Adiatma ${ }^{1}$; Rohimat Nurhasan² ${ }^{2}$ Viani Khoerunnisa ${ }^{3}$ \\ ${ }^{1}$ Universitas Garut \\ adiatmadani@uniga.ac.id \\ ${ }^{2}$ Universitas Garut \\ rohimat.nurhasan@uniga.ac.id \\ ${ }^{3}$ Universitas Garut \\ 24023116380@fekon.uniga.ac.id
}

\begin{abstract}
Abstrak
Tujuan dari penelitian ini adalah untuk meneliti, menganalisis dan mengusulkan pengembangan usaha yang dapat dilakukan oleh Zocha Handicraft Akar wangi Garut dalam menjalankan usahanya dimana dikemukakan rumusan masalah yang akan dijawab dengan menggunakan pendekatan business model canvas dan analisis SWOT. Metode penelitian yang digunakan adalah metode kualitatif dengan analisis deskriptif. Teknik pengumpulan data dengan wawancara terstruktur terbuka serta dokumentasi. Teknik pemilihan sample dengan purposive sampling. Hasil penelitian identifikasi Business Model Canvas ini dapat memberikan opsi pengembangan strategi bisnis yang tepat untuk Zocha di setiap elemen. Elemen segmen pelanggan berfokus pada kelas menengah ke atas dan pada saat ini di kalangan wisatawan, elemen proposisi nilai berfokus pada layanan, pemenuhan produk kustom, serta paket edukasi yang menyenangkan. Elemen saluran dilakukan dengan peningkatan promosi melalui media online. Unsur komunikasi yang baik hubungan pelanggan dalam trust in trust, memberikan kemudahan bagi konsumen dalam mengakses secara online. Unsur keuntungan aliran pendapatan selain penjualan produk dapat bersumber dari penjualan souvenir dan kartu anggota. Elemen sumber daya utama adalah sumber daya fisik, intelektual, manusia, keuangan. Elemen kegiatan utama adalah fokus pada proses produksi, promosi di hari besar dan saat ini fokus pada kunjungan galeri \& pabrik. Elemen kunci dari kemitraan perusahaan diarahkan untuk bekerja sama dengan UKM lainnya. dan terakhir elemen struktur biaya berfokus pada biaya tetap dan biaya variabel. Kemudian dengan melakukan analisis faktor internal dan faktor eksternal kemudian menganalisis alternatif strategi menggunakan matriks SWOT juga membentuk Business Model Canvas saat ini.
\end{abstract}

Kata kunci: Analisis SWOT, Business Model Canvas, Pengembangan, Strategi Bisnis.

\begin{abstract}
The purpose of this research is to research, analyze and propose business development that can be done by Zocha Handicraft Akar wangi Garut in running its business where it is put forward on the formulation of problems that will be answered
\end{abstract}


using the approach of business model canvas and SWOT analysis. The research method used is qualitative method with descriptive analysis. Technical data collection with open structured interviews as well as documentation. Informant selection techniques with purposive sampling. The results of this business model canvas identification research can provide the right business strategy development options for Zocha in each element. The customer segment element focuses on the upper middle class and at the moment among tourists, the value propositions element focuses on service, custom product fulfillment, as well as fun educations packages. Channel elements are done with increased promotion through online media. Elements of good communication customer relationships in trust in trust, providing convenience for consumers in accessing online. Elements of revenue streams advantages in addition to the sale of products can be sourced from the sale of souvenirs and member cards. Key resources elements are physical, intellectual, human, financial resources. The key activities element is to focus on the production process, promotion on the big day and currently focus on galery \&factory visit. Key elements of the company's partnershios are directed to cooperate with other SMEs. and lastly the cost structure element focuses on fixed costs and variable costs. Then by conducting an analysis of internal factors and external factors then analyzing alternative strategies using the SWOT matrix also forms the current canvas business model.

Keywords: Business Model Canvas, Business Strategy, Development, SWOT Analysis

\section{Pendahuluan}

Menurut World Bank Group (www.doingbusiness.org, 2020), peringkat yang tinggi menunjukan peraturan untuk berbisnis yang lebih baik (biasanya lebih sederhana), dan kuatnya perlindungan atas hak milik. Penelitian empiris yang didanai oleh Bank Dunia untuk membuktikan manfaat dari dibuatnya indeks ini, menunjukan bahwa efek dari perbaikan berbagai peraturan terhadap pertumbuhan ekonomi sangat besar. Indonesia di tahun 2020 ini menduduki peringkat ke 73 menurut survei Bank Dunia dengan score 69,6 yang sebelumnya menduduki score 62,8.

Kemudahan dalam berbisnis menjadi salah satu strategi peluang atau bisa menjadi ancaman tersendiri, karena dengan peluang maka kemudahan berbisnis itu sendiri membuat pangsa pasar menjadi luas. Disamping itu, ada ancaman tersendiri untuk kemudahan bisnis yaitu memerlukan daya saing untuk berkompetisi di pasar. Daya saing sebagai keunggulan suatu kegiatan bisnis ditentukan oleh memahami perubahan pelaku ataupun organisasi yang melibatkan kombinasi pemikiran, proses, serta pemanfaatan efektif dari teknologi dan manusia dalam menghasilkan suatu produk yang berbeda ataupun lebih baik.

Daya saing juga berperan penting untuk usaha mikro, kecil dan menengah (UMKM), karena UMKM memberikan kontribusi pada PDB (Produk Domestik Bruto) Indonesia sebesar $60 \%$. Namun pada saat ini sumbangan UMKM terhadap ekspor baru mencapai 14,5\% atau lebih rendah dibanding UMKM di Thailand, Vietnam maupun Korea. Sumber (http://www.depkop.go.id , 2018).vEkonomi kreatif menopang perekonomian bangsa karena kreativitas akan menciptakan inovasi sehingga meningkatkan nilai tambah lebih tinggi. Howkins (2001) mendefinisikan ekonomi kreatif sebagai the creation of value as a result of idea (penciptaan nilai sebagai hasil dari penjabaran ide-ide). Howkins (2001) menjelaskan ekonomi kreatif sebagai "kegiatan ekonomi dalam masyarakat yang menghabiskan sebagian besar waktunya untuk menghasilkan 
ide, tidak hanya melakukan hal-hal yang rutin dan berulang. Karena bagi masyarakat ini, menghasilkan ide merupakan hal yang harus dilakukan untuk kemajuan." Ekonomi di Indonesia didominasi oleh 3 subsektor yaitu kuliner, fashion, kriya. Salah satunya subsektor kriya yang menyumbang sebesar 15,7\% untuk ekonomi Indonesia. Subsektor Kriya juga menyumbang $37 \%$ untuk ekspor ekonomi kreatif dan menduduki posisi ke-2 terbesar.

Salah satu UKM yang bergerak dalam sektor ekonomi kreatif dengan subsektor kriya adalah Zocha Graha kriya Handicraft. UKM ini berada di Jawa Barat tepatnya kota Garut, bergerak di bidang ekonomi kreatif subsektor kriya yaitu kerajinan tangan akar wangi. Akar wangi merupakan tanaman khas kebanggaan kota Garut. Menurut owner Zocha saat melakukan wawancara pra penelitian, akar wangi tumbuh bisa dimana saja tetapi hanya tumbuh subur di wilayah dunia yaitu Haiti, Jamaika dan di Garut akar wangi tumbuh subur dan memiliki kualitas wangi yang baik. UKM Zocha belum menentukan strategi bisnis karena dilihat dari segmen pelanggan saat ini berjalan tergantung apa adanya bisnis saja. Dalam hal mencari SDM juga mengalami kesulitan dalam mencari SDM yang kompeten saat ini karena Zocha ini berhubungan dengan kerajinan tangan yang membutuhkan SDM yang mempunyai ketekunan, telaten, dan inisiatif. Sejauh ini bisnis networks yang diciptakan hanya berdasarkan loyalitas pelanggan saja yaitu yang sengaja mencari produk Zocha saja, perluasan pelanggan juga belum dimaksimalkan karena pelanggan selama ini hanya berasal dari bisnis networks yang sama sejak 10 tahun yang lalu.

Menurut Chesbrough (2006), strategi usaha yang dijalankan oleh perusahaan tidak akan dapat berjalan maksimal jika tidak didasari oleh pengkajian dan perumusan model bisnis yang tepat. Menurut Osterwalder \& Pigneur (2012), menyatakan bahwa sebuah model bisnis menggambarkan dasar pemikiran tentang bagaimana organisasi menciptakan, memberikan dan menangkap nilai. Model bisnis harus sederhana, relevan dan mudah dipahami. Model bisnis tersebut digambarkan dalam sembilan blok yang tersusun dalam model bisnis business model canvas. Oleh karena itu, penelitian ini dilakukan untuk mengetahui gambaran strategi bisnis menggunakan business model canvas juga untuk bertujuan mengidentifikasi serta menganalisis kondisi dari faktor eksternal dan internal bisnis untuk nantinya dikaitkan dengan gambaran model bisnis.

\section{Tinjauan Pustaka}

\subsection{Strategi Bisnis}

Strategi bisnis dalam manajemen bergerak dinamis karena strategi bisnis dilakukan secara terusmenerus juga terus dilakukan peninjauan ulang dalam setiap implementasinya. Menurut Chesbrough (2016), strategi usaha yang dijalankan oleh perusahaan tidak akan dapat berjalan maksimal jika tidak didasari oleh pengkajian dan perumusan model bisnis yang tepat.

Menurut David (2012), memberi pengertian bahwa manajemen strategis dapat didefinisikan sebagai seni dan pengetahuan dalam merumuskan, mengimplementasikan, serta mengevaluasi keputusan-keputusan lintas fungsional yang memampukan sebuah organisasi mencapai tujuannya. David (2012) mengemukakan proses manajemen strategis terdiri atas tiga tahap yaitu perumusan strategi, penerapan strategi, penilaian strategi.

\subsection{Kanvas Model Bisnis (Business Model Canvas)}

Business Model Canvas (BMC) salah satu alat strategi yang digunakan untuk mendeskripsikan sebuah model bisnis dan menggambarkan dasar pemikiran tentang bagaimana organisasi menciptakan, memberikan, dan menangkap nilai. 


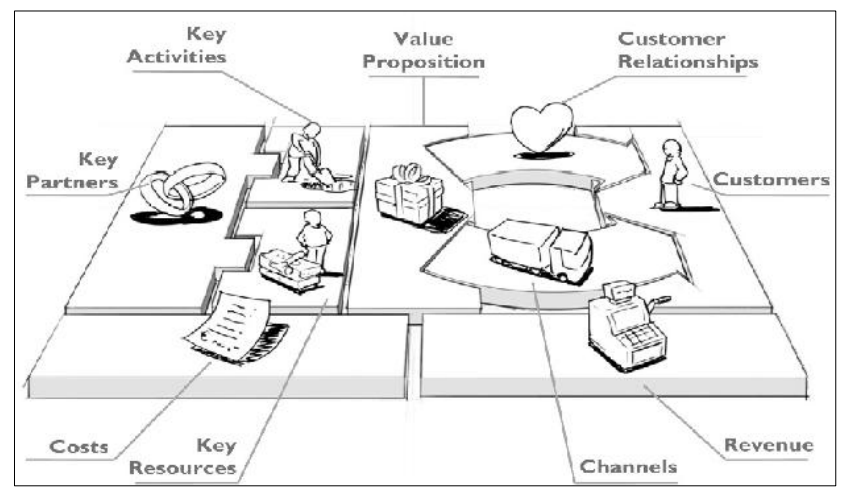

Gambar 1: Gambar dengan gaya kotak

Model bisnis kanvas digambarkan melalui sembilan blok bangunan dasar yang menunjukkan logika bagaimana perusahaan bermaksud untuk menghasilkan uang. Sembilan blok ini mencakup empat bidang utama bisnis yaitu pelanggan, penawaran, infrastruktur, dan kelayakan keuangan.

\subsection{Kerangka Pemikiran}

Setelah peneliti mengetahui gambaran posisi bisnis atas strategi bisnis yang telah diterapkan selama ini dan perkembangannya sejauh mana, lalu peneliti akan mengidentifikasi dan melakukan penjabaran model bisnis dengan pendekatan dari sembilan balok business model canvas. Setelah mengidentifikasi elemen-elemen $B M C$, peneliti akan menganalisa dengan menggunakan SWOT. Analisis SWOT bertujuan mengidentifikasi kekuatan dan kelemahan suatu organisasi.

Zocha Biaya operasional

Menggambarkan lalu mengembangkan bisnisnya dengan konsep atau pendekatan yang berbeda dari yang sebelumnya ada
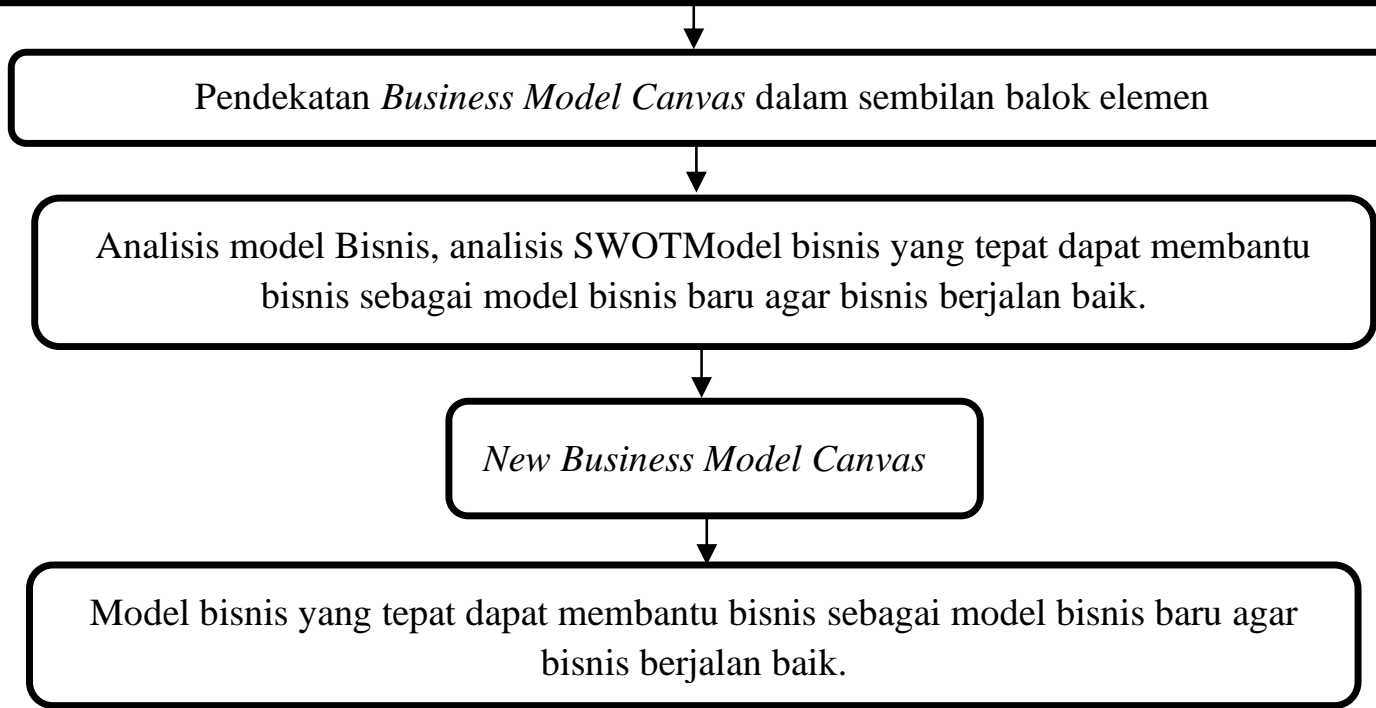

Gambar 2: Kerangka pemikiran 


\section{$3 \quad$ Metodologi Penelitian}

Metode penelitian yang digunakan adalah metode kualitatif dengan pendekatan analisis deskriptif. Penelitian dengan metode kualitatif ini bertujuan untuk membuat deskripsi, memberikan gambaran atau lukisan dari business model canvas terhadap hubungan antar fenomena yang diteliti. Setelah itu, untuk mengetahui penilaian melalui bobot dan rating diperoleh melalui analisis SWOT sehingga dapat diketahui gambaran mengenai faktor internal dan eksternal dari Zocha Handicraft Garut.

Dalam penyajiannya, penelitian ini memberikan gambaran model bisnis dengan menggunakan tools Business Model Canvas (BMC) dan dibantu dengan menggunakan analisis SWOT di setiap elemen Business Model Canvas (BMC) pada Zocha Handicraft Garut.

Data yang digunakan dalam penelitian ini adalah data primer dan data sekunder. Teknik pengumpulan data dengan observasi, wawancara, studi kepustakaan, dan kuesioner yang diisi oleh Pimpinan (owner) dan 1 pegawai Zocha. Sumber data dalam penelitian ini terdiri dari 2 orang informan yaitu kepala operasional (manajer), dan pegawai. Teknik analisis data dalam penelitian ini terdiri dari: pengumpulan data, reduksi data, penyajian data dan penarikan kesimpulan. Teknik keabsahan data dalam penelitian ini dengan menggunakan triangulasi, dan bahan referensi.

\section{$4 \quad$ Hasil Penelitian dan Pembahasan}

Hasil pemetaan ini digambarkan menjadi suatu model analisis yaitu business model canvas. Penggambaran model bisnis ini bertujuan untuk mengetahui perencanaan bisnis yang akan disesuaikan dengan perusahaan juga elemen-elemen bisnis. Pada bagian selanjutnya model bisnis tersebut akan dievaluasi, lalu pada bagian terakhir penelitian ini akan memberikan rekomendasi perubahan konten model bisnis kanvas berdasarkan analisis SWOT dengan kembali menggunakan business model canvas sehingga menghasilkan New Business Model Canvas.

\subsection{Business Model Canvas}

Setelah melakukan pengumpulan data dengan teknik observasi dan wawancara, maka selanjutnya dapat digambarkan menjadi suatu model analisis yaitu business model canvas. 


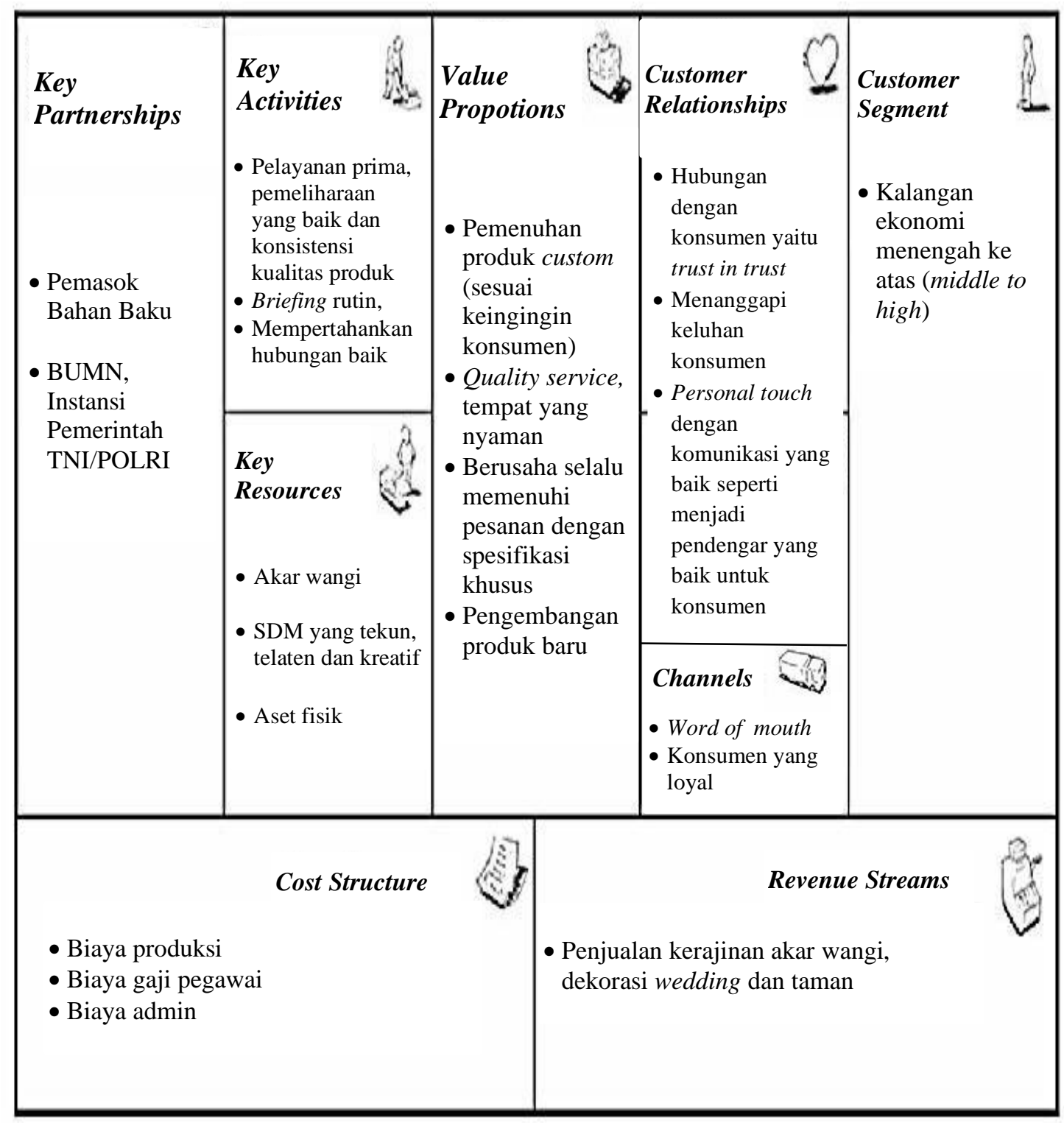

Gambar 3: Business model canvas

\subsection{Analisis $S W O T$}

Nilai kekuatan yang tinggi yang dimiliki Zocha yaitu faktor akar wangi itu sendiri yang merupakan tanaman khas Kabupaten Garut dan pada saat ini hanya Zocha yang baru memproduksi kerajinan tangan yang berbahan dasar akar wangi. Nilai kekuatan yang tinggi lainnya berasal dari faktor produk custom, zocha menjadikannya kekuatan untuk mempertahankan loyalitas dan menarik calon pelanggan, nilai kekuatan yang tinggi juga terletak pada selalu menjalin hubungan baik dan ramah dengan pemasok utamanya itu pelanggan.

Didalam faktor internal perusahaan juga terdapat faktor kelemahan (weakness). Nilai kelemahan yang tertinggi yaitu faktor SDM (sumber daya manusia) yang kurang memadai, berdasarkan hasil wawancara dengan informan menurutnya permintaan akar wangi cukup tinggi kendati demikian yang menjadi kendala adalah sulit mendapatkan SDM untuk perajin yang terampil. Nilai 
kelemahan yang tinggi berasal dari tempat parkir yang terbatas, mengutip (Lupiyoadi, 20016) menyatakan lokasi berarti berhubungan dimana perusahaan harus bermarkas dan melakukan operasi, oleh karena itu lokasi sangat penting bagi perusahaan, karena akan mempengaruhi kedudukan perusahaan dalam persaingan dan menentukan kelangsungan hidup perusahaan.

Dalam hal peluang (opportunities) faktor ekternal yang memiliki nilai tinggi yaitu peluang kerjasama dengan UKM lainnya karena hal ini bisa menguntungkan jika kerjasama tersebut mendukung faktor kekuatan internal perusahaan seperti langkah untuk memperoleh pelanggan baru dari UKM lainnya, juga untuk pemenuhan SDM yang bisa didapat informasi nya jika bekerjasama dengan UKM lainnya.

Yang memiliki nilai yang tinggi dalam hal peluang ialah pengembangan factory dan galery visit seiring dengan peluang perluasan galeri untuk membangun merek perusahaan dan reputasi perusahaan. Zocha bekerjasama dengan mitra dagang khusus untuk tingkat pengendalian tinggi atas harga dan jasa, mitra dagang tersebut juga bisa dijadikan mitra kerjasama dalam pengembangan konsep factory dan galery visit yang diberikan guna untuk meningkatkan jumlah konsumen. Perkembangan teknologi untuk pemasaran juga menjadi peluang yang bagus karena memiliki nilai tertinggi juga perkembangan teknologi saat ini dapat dijadikan sebagai pemasaran produk agar lebih terkenal di masyarakat juga memudahkan akses masyarakat dalam mencari informasi produk. Yang menjadi ancaman tertinggi yaitu munculnya pesaing bisnis memang pada saat ini hanya Zocha yang memproduksi kerajinan akar wangi di Garut. 


\section{Tabel 1: Matriks SWOT}

\begin{tabular}{|c|c|c|}
\hline EFAS & $\begin{array}{l}\text { Kekuatan: } \\
\text { 1. Akar wangi merupakan } \\
\text { tanaman khas dari Garut } \\
\text { diproduksi Zocha menjadi } \\
\text { kerajinan tangan yang } \\
\text { berkualitas } \\
\text { 2. Produk dibuat khusus } \\
\text { berdasarkan pesanan serta } \\
\text { keinginan dari pembeli } \\
\text { 3. Souvenir dari Kabupaten } \\
\text { Garut bagi wisatawan } \\
\text { 4.Inovasi produk yang } \\
\text { berkualitas } \\
\text { 5. Selalu menjalin hubungan } \\
\text { baik dan ramah dengan } \\
\text { pemasok } \\
\text { 6. Loyalitas pelanggan }\end{array}$ & $\begin{array}{l}\text { Kelemahan: } \\
\text { SDM (sumber daya manusia) } \\
\text { yang kurang memadai } \\
\text { Kurang memaksimalkan media } \\
\text { sosial untuk promosi } \\
\text { Lokasi yang kurang Strategis } \\
\text { Memiliki tempat Parkir Terbatas } \\
\text { Harga produk yang mahal } \\
\text { Toko hanya mengandalkan } \\
\text { customer untuk datang ke toko }\end{array}$ \\
\hline $\begin{array}{l}\text { Peluang: } \\
\text { Kerjasama dengan UKM lainny } \\
\text { Pengembangan factory dan } \\
\text { galery visit } \\
\text { Perluasan galeri (tempat) } \\
\text { Bekerjasama dengan event } \\
\text { organizer untuk dekorasi acara } \\
\text { dan merchandise acara } \\
\text { Perkembangan teknologi untuk } \\
\text { pemasaran }\end{array}$ & $\begin{array}{l}\text { Strategi SO: } \\
\text { Perusahaan harus membangun } \\
\text { mitra-mitra baru atau UKM } \\
\text { lainnya untuk menjalin } \\
\text { kerjasama sehingga peluang } \\
\text { bisa dijadikan kekuatan baru. } \\
\text { Perusahaan harus memberikan } \\
\text { penawaran-penawaran terbaik } \\
\text { dan unik agar dapat menarik } \\
\text { banyak konsumen baru dan } \\
\text { membuat konsumen lama agar } \\
\text { tetap loyal terhadap perusahaan. } \\
\text { Memanfaatkan teknologi untuk } \\
\text { memperluas segmen pelanggan } \\
\text { dan memperkenalkan produk } \\
\text { inovasi }\end{array}$ & $\begin{array}{l}\text { Strategi WO: } \\
\text { Melayani pasar menengah ke } \\
\text { bawah untuk menjangkau } \\
\text { pelanggan lainnya dan perluasan } \\
\text { pasar } \\
\text { Perusahaan harus menghindari } \\
\text { mengejar keuntungan yang } \\
\text { bersifat sesaat dengan } \\
\text { mengabaikan untung yang kecil } \\
\text { Mencoba perluasan tempat } \\
\text { untuk pengembangan galery dan } \\
\text { factory visit }\end{array}$ \\
\hline $\begin{array}{l}\text { Ancaman: } \\
\text { Munculnya pesaing bisnis } \\
\text { Harga minyak akar wangi naik } \\
\text { Produk yang ditiru pesaing } \\
\text { bisnis } \\
\text { Peningkatan biaya produksi jika } \\
\text { harga bahan baku naik } \\
\text { Perubahan selera konsumen }\end{array}$ & $\begin{array}{l}\text { Strategi ST: } \\
\text { Senantiasa menjalin hubungan } \\
\text { yang baik dengan pelanggan dan } \\
\text { selalu menjalin komunikasi yang } \\
\text { harmonis dengan pemasok- } \\
\text { pemasok terpercaya } \\
\text { Lebih aktif melihat kondisi pasar } \\
\text { saat ini terhadap kemungkinan } \\
\text { munculnya pesaing yaitu } \\
\text { mempertahankan kualitas } \\
\text { produk, inovasi prosuk dan } \\
\text { promosi } \\
\text { Setiap bagian internal } \\
\text { perusahaan dapat bersinergi satu } \\
\text { sama lain }\end{array}$ & $\begin{array}{l}\text { Strategi WT: } \\
\text { Menambah tenaga pemasar } \\
\text { untuk kegiatan promosi dan } \\
\text { meningkatkan penjualan } \\
\text { Secara rutin dan berkala } \\
\text { melakukan evaluasi dalam } \\
\text { membuat strategi bisnis } \\
\text { Melihat kondisi pasar dan } \\
\text { melalukan penelitian untuk } \\
\text { antisipasi pesaing dan selera } \\
\text { pasar }\end{array}$ \\
\hline
\end{tabular}

\subsection{New Business Model Canvas / Kondisi Bisnis Model Kanvas Saat Ini}

Hasil penelitian ini membentuk pemetaan model bisnis kanvas dengan memadukan hasil analisis bisnis model kanvas dengan analisis swot menghasilkan kondisi bisnis model kanvas seperti berikut. 


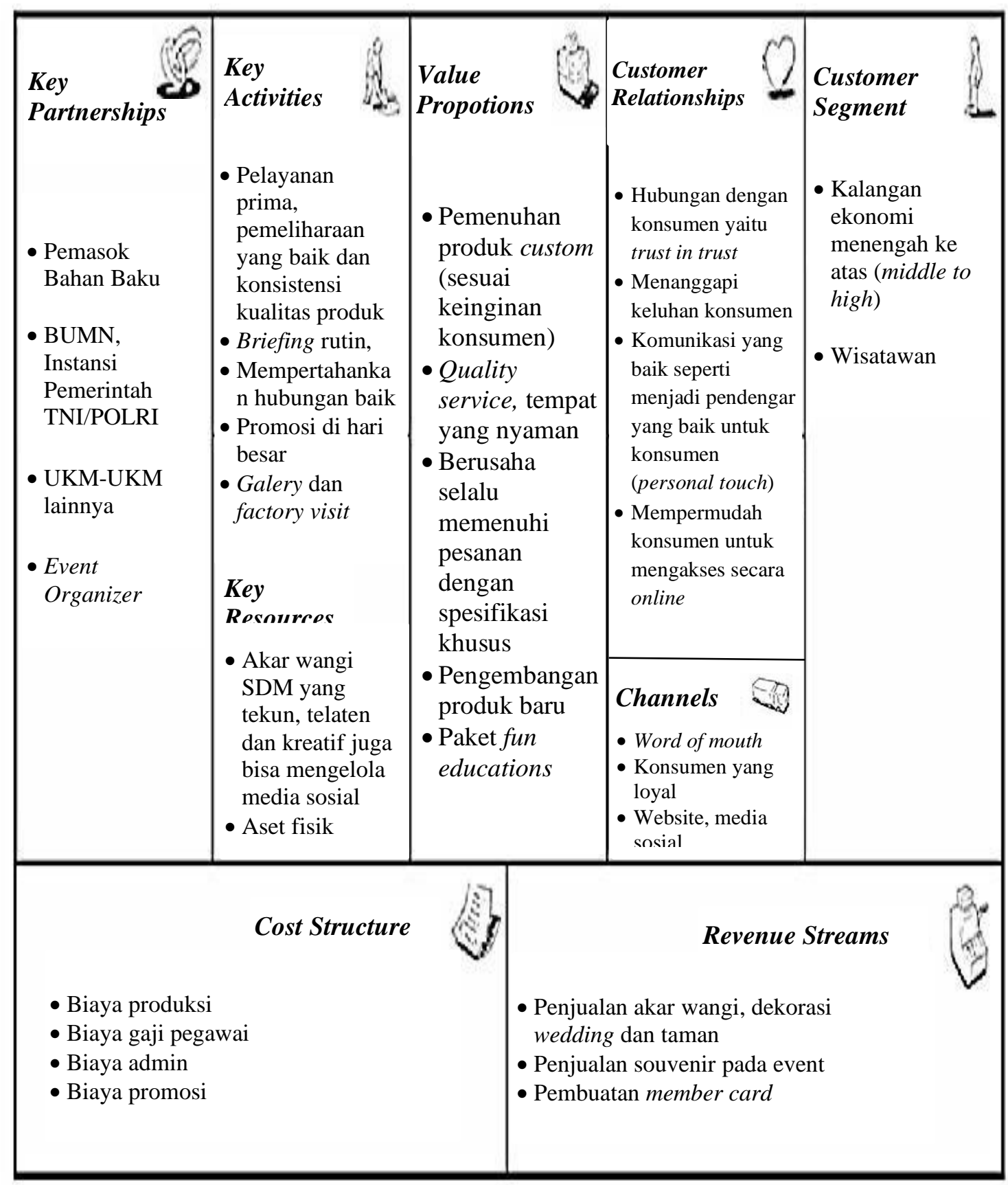

Gambar 4: Kondisi bisnis model kanvas

\section{$5 \quad$ Simpulan dan Saran}

Didapat kondisi bisnis model kanvas saat ini berdasarkan sembilan blok elemen kunci yang terdapat pada business model canvas (BMC), yang didukung dengan analisis SWOT hasilnya adalah sebagai berikut:

1. Zocha Handicraft akar wangi dapat mengimplementasikan business model canvas atau BMC. Dilihat dari segmen pelanggan yang menjadi perhatian adalah segmen pelanggan menengah ke atas, dengan menerapkan proporsi nilai (Value propotions) yang menguntungkan menjadi sesuatu yang menguntungkan dalam pengembangan bisnis yang 
mana akan mempengaruhi pada arus pendapatan (Revenue Streams), memperluas jaringan channels untuk meningkatkan kesadaran masyarakat terhadap produk, meningkatkan customer relationships juga menjaga kemitraan guna keberlangsungan usaha, stuktur dana (Cost Structure) dengan memperhatikan key resources, key activities, dan key partnership.

2. Berdasarkan SWOT (strength, weakness, opportunity, dan threats) terdapat 12 alternatif strategi yang dapat digunakan. Strategi tersebut diperoleh dalam bentuk strategi SO (strengths-opportunity), WO (weakness-threats), ST (strengths-threats), dan WT (weakness-threts). Sebelas alternatif strategi tersebut diantaranya:

a. Perusahaan harus membangun mitra-mitra baru atau UKM lainnya untuk menjalin kerjasama sehingga peluang bisa dijadikan kekuatan baru.

b. Perusahaan harus memberikan penawaran-penawaran terbaik dan unik agar dapat menarik banyak konsumen baru dan membuat konsumen lama agar tetap loyal terhadap perusahaan.

c. Memanfaatkan teknologi untuk memperluas segmen pelanggan dan memperkenalkan produk inovasi.

d. Melayani pasar menengah ke bawah untuk menjangkau pelanggan lainnya dan perluasan pasar.

e. Perusahaan harus menghindari mengejar keuntungan yang bersifat sesaat dengan mengabaikan untung yang kecil.

f. Mencoba perluasan tempat untuk pengembangan galery dan factory visit.

g. Senantiasa menjalin hubungan yang baik dengan pelanggan dan selalu menjalin komunikasi yang harmonis dengan pemasok-pemasok terpercaya.

h. Lebih aktif melihat kondisi pasar saat ini terhadap kemungkinan munculnya pesaing yaitu mempertahankan kualitas produk, inovasi prosuk dan promosi.

i. Setiap bagian internal perusahaan dapat bersinergi satu sama lain.

j. Menambah tenaga pemasar untuk kegiatan promosi dan meningkatkan penjualan.

k. Secara rutin dan berkala melakukan evaluasi dalam membuat strategi bisnis.

1. Melihat kondisi pasar dan melalukan penelitian untuk antisipasi pesaing dan selera pasar.

3. Berdasarkan analisis SWOT sebagai analisis pendukung untuk menciptakan new business model canvas / kondisi bisnis model kanvas saat ini yaitu, di blok elemen customer segment terdapat perluasan segmen baru di kalangan wisatawan, blok elemen value propositions terdapat paket fun educations, blok elemen channels terdapat website dan media sosial, blok elemen customer relationships dengan mempermudah konsumen untuk mengakses secara online, blok elemen revenue streams terdapat penjualan souvenir pada event juga pembuatan member card, blok elemen key resources terdapat tenaga pemasar, blok elemen key activities terdapat promosi di hari besar dan konsep galery dan factory visit, blok elemen key partnerships terdapat mitra UKM-UKM lainnya juga event organizer, dan blok elemen cost structure terdapat biaya promosi.

Berdasarkan penelitian yang dilakukan penelitian strategi bisnis Zocha Handicraft Akar wangi Garut menggunakan analisis business model canvas, maka peneliti ingin memberikan saran-saran sebagai berikut:

1. Sebaiknya mengembangkan dan memperjelas secara rinci,bisa dimulai dengan visi dan misi perusahaan yang maksudnya perusahaan memiliki tujuan yang harus dicapai dalam jangka panjang meyakinkan stakeholders untuk meningkatkan semangat kerja dan komitmen, memiliki penangggung jawab khusus atau dikelola khusus oleh orang yang profesional bidang media sosial, merencanakan konsep yang akan dikembangkan dan mengimplementasikannya.

2. Sebaiknya Zocha memikirkan langkah yang tepat untuk mengambil strategi kedepannya untuk pengembangan bisnis dan sebagai alternatif pengambilan keputusan, kondisi internal Zocha perusahaan kuat dilihat dari matriks IFE seharusnya Zocha bisa menjadikan 
kekuatan internal tersebut sebaiknya untuk menutupi kelemahan juga Zocha Handicraft merespon dengan sangat baik terhadap peluang dan ancaman seperti hal nya tergambar dalam elemen-elemen business model canvas yaitu dalam hal customer segment yang bisa perluas dari pelanggan lama dan yang baru seperti di kalangan wisatawan, SDM yang kurang memadai sebaiknya memanfaatkan key partnerships seperti bekerja sama dengan UKM lainnya untuk mendapatkan informasi SDM yang inovatif dan terampil, ancaman dari luar sebaiknya memanfaatkan value propotions yang baru seperti fun educations juga perluasan channel menggunakan media sosial oleh SDM yang secara khusus mengelola media sosial.

3. Mempertimbangkan hasil perancangan strategi dari business model canvas untuk menjadi pilihan strategi untuk persaingan, juga mempermudah pengembangan bisnis.

\section{Daftar Pustaka}

Chesbrough, H. (2006). Open Business Models: How To Thrive In The New Innovation Landscape. American: Harvard Business School Press.

David, F. R. (2012). Strategic Management Concepts. Jakarta: Salemba Empat.

Howkins, J. (2001). The Creative Economy. Inggris: Penguins Book.

http://www.depkop.go.id . (2018). Retrieved Maret Senin, 2020, from Kementerian Koperasi dan UKM.

Lupiyoadi. (20016). Manajemen Pemasaran Jasa Berbasis Kompetensi. Jakarta: Salemba Empat.

Osterwalder, A., \& Pigneur, Y. (2012). Business Model Generation. Jakarta: Elex Media Komputindo.

R Faozy, A Ramdhani, R Nurhasan (2020) Analisis Faktor - Faktor Yang Mendorong Kinerja UKM pada Industri Wajit. Business Innovation and Entrepreneurship Journal 2 (1), 1519.

www.doingbusiness.org. (2020). Retrieved Februari 2020, from Doing Business Website: www.doingbusiness.org 